\title{
The discursive construction of dyslexia by students in higher education as a moral and intellectual good.
}

\section{Cameron, H \& Billington, $T$}

\begin{abstract}
Interest in dyslexia as a topic of discussion in education, and in the media, runs through peaks and troughs. Dyslexic students in higher education must navigate their way through the possible meanings attached to the label, appropriating some and rejecting others, yet needing the label as a means to access support. The aim of this paper is to explore the ways in which dyslexic university students constructed dyslexia and being dyslexic as moral issues during two focus group conversations. These conversations were discursively analysed with reference to Gee (2005) and Willig (2008). Three key themes emerged following analysis: the interaction between the power of the grade as a marker of worth and the status of the dyslexia label; the tensions between acknowledging difficulties with writing and the construction of high literacy as morally aspirational; and the uncertain, yet persistent, construction of dyslexia as a valuable label and a moral good.
\end{abstract}

dyslexia; higher education; discourse, ideology 


\section{Introduction}

Dyslexia is widely described as an innate cognitive or neurological deficiency which has an impact upon reading ability (Nicolson and Fawcett, 2008). However, according to certain leading figures in the field, 'understandings of dyslexia are often impoverished, misleading and incorrect' (Elliott \& Grigorenko, 2014b: 579). There are ongoing disagreements about what exactly dyslexia is and where it comes from; how prevalent it is; whether it is one thing or many; how it is identified; and how this knowledge should inform policy and education (Stanovich, 2005; Elliott \& Grigorenko, 2014a; Ho, 2004). Julian Elliott and Elena Grigorenko (2014a) question the meaning of the word from the scientific perspective, and consider that we might be better off without it. In a context where such conclusions are convoluted and sometimes misrepresented in the mainstream media, it becomes important to ask how students labelled as dyslexic manage the varied conceptions of dyslexia they are confronted with. The perspective in this paper is that discourses of dyslexia and disability are laden with ideological messages about the different moral status of different kinds of learner and learning in higher education. Although a label like dyslexia may appear to be a neutral one, offering a route to fairer participation, it is partially a product of a long history of labelling and sorting of people according to presumed individual differences constructed in particular social and political contexts (Danziger, 1990; Ho, 2004; see also Hacking, 1995, on the role of moral values in the construction of labels). However, this does not mean the label is redundant. A thorough understanding of what the label can mean to people who receive it, and an exploration of their related experiences should be essential elements in conversations about labelling and participation in education and beyond (Macdonald, 2009) and it is these elements which are missing from the perspective of Elliot and Grigorenko summarised above.

Psychological categorisation of people thought to be particularly gifted, deficient or otherwise not 'normal' has a long history (Danziger, 1990). From its conception, psychology constructed knowledge about individuals 'around the pole of abnormality' (Rose, 1985: 5), and so effectively did it do this, that today this knowledge can appear as common sense. Labels for those whom were considered intellectually or morally deficient one hundred and 
fifty years ago, such as 'idiot' and 'moron', have become part of everyday discourse, and new labels have become the formal, psychological and medical categories of person who lie outside the 'norm' (see the DSM-V, via the American Psychological Association, 2013). Although scientifically sanctioned, such labels are not immune from social judgment. Dyslexia is one such label, which was not long ago called 'reading retardation' (Benton \& Pearl, 1978), and is still at risk from associations of moral inferiority perhaps partly because of historical associations with 'retardation' or other physical or mental 'abnormalities' and moral degradation (Jackson, 1996). Along with talk of dyslexia as a 'disease' (e.g. Rutter, 1978), and its neat measurement and statistical description following psychometric tests, dyslexia arguably became one of those, apparently neutral, 'things' made by science and meant those labelled became available to 'education' (treatment).

Being dyslexic is arguably more socially acceptable than being labelled a 'garden variety poor reader' which is less specific and more easily connected ideas about moral and intellectual inferiority (Gibbs \& Elliott, 2010: 298; see also Ho, 2004, for a similar point). And indeed there is some overt movement within cognitive psychology towards a more positive framing of dyslexia (see Nicolson, 2015). However, being labelled dyslexic does not appear to lead to a smoother or more positive learning experience (Mugnaini et al, 2009). Furthermore, dyslexia can still be constructed as morally questionable, in a large part because people whose reading and writing skills are considered 'inadequate' are perceived as being of less value (Tanner, 2009). Those who seek the label (for themselves or their children) have also been accused of subscribing to a 'convenient fiction' to explain academic struggles (McDermott et al. 2006) or lack of achievement (Riddick, 1995). This accusation seems particularly likely following periodic proclamations in the media of dyslexia as a myth and an excuse (e.g. Daley, 2009). There is also the suggestion that institutions seek the label for their students for financial advantage (Soler, 2009).

There are now many students with the label of dyslexia who go to university and who achieve their degrees, but their experiences through tertiary education and their identities as dyslexic are shaped by the conceptions of dyslexia they take on (Pollack, 2005). Lecturing staff also appear to have very different understandings of dyslexia and different perspectives upon what adjustments are fair (Cameron and Nunkoosing, 2012). What emerges is a picture of dyslexic students navigating their way through learning at university, having to accept the label in 
certain contexts and wanting to throw it off in others, while keeping an eye upon how their label colours their standing in different environments. The need to demonstrate a high standard of literacy in order to prove oneself intellectually and morally seems to be an ongoing pressure (Collinson \& Penketh, 2009). Not only is the ability to produce erudite 'academic' writing a sign of status and intelligence, it may also be seen as a sign of wisdom and worthiness (Collinson \& Penketh, 2013); particularly if there are popular fears about diminishing standards of literacy (Lea \& Street, 1998). As such, managing the associations between dyslexia and struggles with literacy also involves managing cultural assumptions about the links between literacy difficulties and potentially diminished value in educational contexts.

This paper reports upon the findings of one part of a larger research project which was interested in identifying discourses of dyslexia and ideological drivers of talk around dyslexia by dyslexic students in higher education. The specific focus here is upon the ways in which focus group participants constructed dyslexia and being dyslexic as moral issues. Attention is given to the ways in which the participants drew upon discourses which produce high literacy and academic success as moral goods, while also managing discourses which reproduce historical associations between learning difficulties and low moral or social status. The approach taken for this particular section of the research is a version of critical discourse analysis which draws upon James-Paul Gee (2005) and Carla Willig (2008), the latter for her interest in discursive resources. This approach is not solely focused upon linguistic elements of talk, but upon narrative, history and more local contexts. The goal is to use this research as a way of opening up conversations within educational institutions around the ideological ways we construct one another, and to better recognise the assumptions we make as students and educators about people with labels of specific learning disability.

\section{Methodology}

One of the aims in analysis was to find the ways in which ideology was apparent in the talk about dyslexia, and how the participants were therefore reproducing particular discursive themes which had histories outside the context in question (after Billig, 2001). Ideology was understood as a wide network of ideas or belief systems (Van Dijk, 2006) that over time have become common sense (Carr \& Hartnett, 1996), and from which our everyday understandings of people and the world may be discursively constructed. Ideology is 
therefore synonymous with hegemonic discourse, or a 'weight' in discourse (Giroux, 1997) that might be obscured in everyday talk.

One way to look for ideology in the text was to follow Willig's (2008) guidance to identify the ways in which the topic is produced from particular ideological perspectives. It is useful here, she says, to look at the use of particular words and groups of words which are associated with particular discourses. Gee (2005) gives a little more detailed set of questions to ask of the text in order to better understand the discursive landscape. He invites the analyst to consider which other texts and discourses are being represented or reproduced in the transcribed text, and he also asks which relationships (between people, things and ideas) seem to be important. Gee's approach $(2005,2009)$ allows for recognition that both the linguistic form of an utterance and the locally informed meaning of an utterance can be important. A word or a phrase may have a widely understood meaning, but this can shift with specific local use and it can be differently understood by different groups of people who have different shared understandings about the world and their places within it. It is with this 'situated' meaning that the current research was most concerned. Therefore, while linguistic elements were part of the story, by no means were these intended to be the primary focus of the current research.

\section{Data collection and analysis}

Two focus group conversations with six and seven participants respectively were undertaken, recorded and transcribed. Focus groups were chosen over interviews because a primary interest was to investigate how the competing discourses of dyslexia which the participants brought into the conversation were managed, maintained or resisted through talk. The focus group context also allowed the researcher to note how the students positioned themselves and each other as dyslexic during the flow of dynamic group conversation. The transcripts were examined for the ways in which participants drew upon wider discourses and ideologies (Gee, 2005, 2009, and Willig, 2008) to construct dyslexia and themselves as dyslexic students. It is one of the themes which emerged during this second stage of analysis which is discussed here. This stage involved careful focus upon each utterance and group of utterances in the text with attention to linguistic structure, narrative, word history and meaning, and the local context and dynamic conversational interaction. Notes were made in the margins of the printed text, and links between different discourses were identified until several key themes 
emerged. What I identified as important is my interpretation as the author, and I fully acknowledge that many other equally valid interpretations are possible.

\section{Ethics}

The School of Education at The University of Sheffield granted ethical approval for the current study. Participants were given an information sheet detailing the aims of the project and informing them of the potential benefit and risks to them from taking part in the study. The participants were thus made aware that in agreeing to take part in a focus group they accepted that their identities would, to some degree, be made known to other participating students whom they may inadvertently meet on a future occasion. They were also asked to consider that they might hear or share personal experiences that they could find uncomfortable or upsetting. The researcher offered detailed information to the ethics board on how these issues would be manage. It was made clear to the participants that they could withdraw at any time. All of the participants fully consented to taking part. Full names were not disclosed during the conversations, and were completely removed from the transcripts and write up. This was in part due to the wish of a number of the participants to remain anonymous, and in part due to potential conflict of interest with the institution in which the participants studied.

\section{Findings and discussion}

Dyslexia is constructed in the focus group texts as a moral label, though this is arguably obscured by its primary construction as a scientific category. Such scientific categories or 'natural kinds' as Hacking names them 'usually present themselves as scientific and hence as value-free, but they have often been brought into being by judgements of good and evil' (Hacking, 1995: 354). This is no less the case here. The discussion below is divided in to three sections which, in turn, consider the interaction between the power of the grade as a marker of worth and the status of the dyslexia label; the tensions between acknowledging difficulties with writing and the construction of high literacy as morally aspirational; and the uncertain, yet persistent, construction of dyslexia as a valuable label and a moral good.

Key to transcription: 
[ ] - square brackets indicate overlapping speech

, - comma indicates brief pause

. - full stop indicates downward intonation and longer pause

\section{The power of the grade}

Throughout the focus group conversations the participants' position within the educational system was the most prominent in the stories they told of being 'diagnosed', and 'succeeding' or 'failing'. Particularly prominent in the conversations were grades given for coursework and exams, teachers' judgments of their ability, and comparison of themselves with peers. Below are a couple of extracts in which some of the participants talk about their frustration with their progress at school:

C: well, when I was at high school, in, like year year ten or eleven, erm, with my English teacher, I didn't really get on with her, and I think it was because maybe we both didn't know that I was dyslexic, but my grammar and my English was both really rubbish, and I was getting like Ds and Cs when I was predicted As, and I just couldn't understand, like I was doing everything she told me, like I went for extra help [and ev] erything [and] it just got really

H: [yeah ] [yeah]

C: frustrating that she was, like, no, it's still wrong. And she wasn't very positive about it? And it was really frustrating to be, like, well I'm doing what you've asked me to do, but it's still [not], still not getting the grades, [erm]
$H:$
[yeh]
$[y u h]$

B: I think it was frustrating with like English coursework, like the, I didn't seem to be able to improve [it, erm] 
R: you know, erm, it would be a C, and I'd rewrite it, erm and then, you know try and improve and, would there's be writing all over it and I would you know, rewrite it, and it would still be a $C$, hhh. Seemed so unfair.

$R$ : and it was was just frustrating esp especially because I was in a class for gifted and talented, class for gifted English people and that that was at the end of year 9 and then by the end of GCSEs I was getting Cs and others in those classes were getting As and A stars, and I was supposed to be this gifted and talented student and I was getting Cs hhh.

H: yeah yeh.

D: $m m m$

In the first of the extracts above, the 'when' of her experience, as marked by her school year, and the presence of her English teacher is presented as the forefront to C's experience of frustration. '[Y]ear ten or eleven' may be seen deictically here, in that it assumes an understanding in the group of the importance of these years for GCSE exam grades and the run up to A-Levels. 'I' as the subject is maintained throughout this conversational turn: 'I didn't really get on with her...', 'I think...', 'I was dyslexic', 'I was predicted As', 'I just couldn't understand...', 'I was doing everything she told me', and 'I went for extra help'. In doing so, $\mathrm{C}$ places the focus on her own agency and action, and therefore we can understand the process through which one gets As as out of C's control; that is, there must have been something else going on. 'I was predicted As' says C, using the passive form where the agent, presumably the teacher, is removed. The passive structure here helps to construct the prediction as the fairer representation of her ability because it hides the human (and presumably more subjective) element, and is an obvious mismatch with the grades she was actually getting. 
In constructing her story, $\mathrm{C}$ also draws on apparently shared understandings of the meanings of grades (Ds and Cs in this case being inferior, and A representing excellence), the role of the teacher in pushing students to raise their grades, and the power relationship between teacher and student in which the former has the role of formally judging the other. We hear the voice of the teacher indirectly with 'she was, like, no, it's still wrong'. The response of the teacher, in this story fits ideologically with the conception of teacher control as one of the 'instruments of normalisation', (Collinson \& Penketh, 2009:10) in that the 'wrongness' of C's work is only something that the teacher can confer, and the student cannot dispute. In this story, however, the power relationship is retrospectively reversed, and $\mathrm{C}$ is able to construct the teacher in a way that positions $\mathrm{C}$ as unfairly treated, hard-working, and deserving of an 'A' grade ('I was predicted As'). The 'She' as the subject refers to the teacher, who 'wasn't very positive' and who apparently unfairly accused $\mathrm{C}$ of lack of effort or ability. The 'I' is always compared favourably to the 'she' in this story. Implicitly, C seems to be saying - 'if only my teacher and I had known I was dyslexic; it would have been different'.

A number of assumptions are arguably present in C's talk in this extract which are maintained by the other participants in later conversational turns: firstly, grades (and qualifications) are generally treated as unproblematic representations of worth and ability; that is, although C did not think Ds or Cs were a fair reflection upon her, she did not question the 'truth' of the grades, but questioned herself: 'I just couldn't understand, like I was doing everything she told me' implying she doubted herself at the time. It is only the retrospective realisation that she is dyslexic which appears to allow $\mathrm{C}$ to construct herself as misunderstood, someone who was, in fact, intelligent. 'Being' dyslexic in this sense was a tool for C to resist others' constructions of her as someone with low status; she is 'safe' in this story from such accusations. C comes close to blaming the teacher for her difficulties, but even the teacher is forgiven in the understanding that she did not know she was dyslexic. The dyslexia provides a useful explanation for $\mathrm{C}$, and means she need not look further afield for answers (for example, to the system that graded her). This use of the label gives strength to concerns in the literature about those who are not given the label of dyslexia, but instead described as having general difficulties with reading or struggling across domains (Ho, 2004; Elliot \& Grigorenko, 2014). However, the label dyslexia does not appear to rid the bearer of stigma altogether: for these participants, it merely helps them shift membership from a group considered inferior to another considered slightly less inferior. The stigma attached to receipt of lower grades and literacy difficulties is not erased (Collinson \& Penketh, 2009). 
$\mathrm{B}$ and $\mathrm{R}$ in the second extract presented above, like $\mathrm{C}$, also narrate their frustration about not achieving the grade they felt they were worthy of, and their lack of understanding about how this could be the case when they were working hard, and when they had the 'intelligence'. The word 'frustrating' is used by C, R and B and they each make similar use of the 'I' as the agentful subject in their reflections. $\mathrm{R}$ uses the modal 'would' repeatedly, which adds force to her positive self-construction by producing her effort and determination as something that was a habit for her at that time. 'Seemed so unfair' said R, not to be given the grade deserved. The word 'seemed' is used in place of the more obvious 'was' here. If R had said it 'was' unfair, a statement of stable fact, she would have been casting the grading system into doubt, when in fact, at this point in the conversation, the emphasis is being placed upon the dyslexia as the culprit, not the system. The past tense of 'seemed' also permits the possibility that it actually turned out not to be unfair; but the fault of the dyslexia. Moreover, 'Gifted and talented' is recognisable as a phrase popularised by educational policy, and offers superior intellectual status. R's use of the term provides an avenue into the conversation for discourses of individual differences, biological determinism, and intellectual hierarchy; a 'gift' is something you are either endowed with naturally or not, and the very existence of 'gifted and talented' pupils automatically produces the 'rest' who are ungifted and talent-less. For R, however, her designation as 'gifted and talented' appeared to construct her as necessarily lazy, as why else would she not be 'succeeding'? 'Being dyslexic' did seem to have an important role to play in reducing the power of the grade, and in offering an explanation for educational 'failure' for some of the participants in these conversations. However, receiving the dyslexia label is unlikely to free a student from their grade-based position in the educational hierarchy, even should it release them from an element of blame (as Elliot \& Grigorenko, 2014, explain).

The following extract is from $\mathrm{R}$, again:

$R:$ for me, it's like my spoken intelligence is a lot higher than my written intelligence, so when I am doing a piece of course work I don't feel it does represent my best [work]

H: [yeah] 
H: yeah

R: $m m m$

The 'for me' in line one and repeated in line 5, performs the function of constructing the speaker, (R), as non-judgemental of others' experiences, and also makes her claim to intelligence incontestable (as no one can dispute what something is like 'for me'). R's presentation of herself as having high 'spoken intelligence' allows her to maintain the concept of 'intelligence' as a thing inside her, while providing an explanation for why she is graded 'poorly' for written work. The dyslexia is an aid to this construction because it provides a socially legitimate reason for how the 'written intelligence' could be recorded as poor, despite the 'true' intelligence being high. For students not in the 'A-grade' category, there is little available in terms of discursive resources to combat the flawed educational identity allotted. Being dyslexic can be part of such resistance. The may be due, in part, to the popular assumption, in some quarters, that the dyslexia label is only given to people with above average 'intelligence' (Elliot \& Grigorenko, 2014), even though this connection has long since been debunked (Stanovich, 1991). There remains an amount of confusion, therefore, which condemns dyslexia to shift awkwardly between being an indicator of flawed intellectual performance and being a mark of intelligence. The moral positions attached to both of these are contradictory.

\section{Aspiring to high literacy}

Although for most of the participants in the current study, difficulties with literacy were narrated as very familiar and significant, there were a number of instances where they constructed a high standard of literacy as a necessary part of being 'academic' and something they aspired to. Below is an extract in which D and $\mathrm{H}$ construct respect for written literacy, and a desire to be accomplished in it.

D: I mean you have to learn to write, in some respects, so probably [a] little bit 
D: is not that bad

\section{D: [but] so [oth] erwise you'll just never learn, or function in society.}

H: [yeh] [no] yeah.

D says 'I mean you have to learn to write'; he softens his statement with 'in some respects' and 'a little bit is not that bad', before directly constructing writing as a social necessity, and even as a moral obligation. His discourse here is quite powerful stuff: he begins 'I mean'. 'I mean' can be a device in spoken English which begins statements of self-evident 'fact', and not just personal opinion. 'I mean' often goes with phrases like 'what you've got to understand is...', or 'the thing is', and here D choses an equally strong second clause: 'you have to learn to write'. Again we hear 'have to' for conferring a rule-based obligation, and one wonders according to whom have we to. In fact, D follows through with the warning of what will happen if one does not follow this rule; namely, the general 'you' will become socially dysfunctional. This accords with an ideological perspective which places literacy as 'fundamental to life' and constructs those who do not learn to read and write to a particular standard as of lesser value (Tanner, 2009: 785). Contexts which require high literacy therefore exclude and stigmatise those who cannot perform in the expected ways (Collinson \& Penketh, 2013). As such, it is quite understandable that dyslexia would be sought as a less damning explanation (Gibbs \& Elliott, 2010).

In the extract below, $\mathrm{N}$ narrates his past difficulty with aspects of written literacy. $\mathrm{N}$ was undertaking $\mathrm{PhD}$ study at the time of this conversation, and like $\mathrm{D}$, had become 'successful' in academia. $\mathrm{N}$ jokingly boasts about his newfound ability to use 'bigger words'. $\mathrm{N}$ perhaps shows here a degree of self-awareness he is playing a game in which the trick is to trick the educators. However, there is still the possibility that in his identity as someone who learnt to play the game, he is left with the concern he is cheating. There is constructed a difference between being able to do academic writing 'naturally' and just tricking people into thinking you do (see Lea \& Street, 1998, on the ideological construction of academic literacy in higher education). 
N: er grammar wise. I really struggled with my grammar, and possibly sentence structure, quite long sentences, etc.

$H: m m$

J: yeah

N: but you know, I learnt a lot, in. yeah. Definitely a positive, [and now] I

$H:$

[mm yeh]

$N$ : can write really well, and people say I write really well, which is all down to the support I got in creating my sentences [and I always ] look $H:$ [yeah that's really interesting]

N: for bigger words when I write as well.

$H: m m m$

N: like 'that's too small; [I can do ]better than that! [where's the thesaurus?]'

General: [hh. Yeah] [hahahahahhhhhhh ]

' $[\mathrm{N}]$ ow I can write really well, and people say I write really well' says N. It is interesting that $\mathrm{N}$ separates what 'I can' do from what 'people say' into two separate clauses; the second clause appears to add validity to the first. We assume that 'people' are significant others whose opinion is to be respected, and after all it is others' opinions of our written work that confers the status. It also reflects the value of writing over oral expression that is wellestablished within higher education (see Friere, 1996, for a discussion of the neglected role of oral communication within the academy). We write for an audience, and at university this is an audience with a particular set of expectations around what constitutes quality. As for D, now that $\mathrm{N}$ has achieved a certain 'standard' in this writing that is acceptable to the academy, it serves him to subscribe to the underlying ideological position; in spite of the fact that achieving the academic status he has may have involved difficulties with literacy not 
experienced by his peers. On the other hand, it may be because of the additional effort $\mathrm{N}$ has had to invest into his academic identity that his allegiance to particular discourses is maintained. The powerful ideas at work within and around our educational institutions mean that it may be difficult to construct a positive identity when one has difficulties with literacy (Lea \& Street, 1998). This may be the case in spite of the potential freedom from blame the dyslexia label can confer (Elliot \& Grigoranko, 2014; Tanner, 2009; Burden, 2005).

\section{Value in the label}

'Cure' is normally a medical term, used in relation to diseases and illnesses, and implies complete removal of 'symptoms', as opposed to 'treatment', which may be independent of 'cure'. The words 'treatment' and 'symptoms' are frequently used in literature and reports on dyslexia, though 'cure' is less common. There have been claims for 'cures', however (see the now discredited Dore Programme, Goldacre, 2006). The idea of a cure for dyslexia was discussed by participants, and in general, being cured was not considered desirable. Here are

$\mathrm{S}, \mathrm{H}$ and $\mathrm{B}$ talking about this question:

S: I'm also like, a little afraid, what if it's that, you cure the dyslexia, and I find I'm still I'm ['Ive still] hhh got all these problems hhhhh

\section{H: $\quad$ [still hh] \\ B: [hhahah]}

S: hh. It' quite frightening. But yes, it's a possibility that, yes, actually, these problems, these problems are possibly just a character defect that I don't sort of, do that.

\section{H: oh hhhhhh.}

Without the label, the same problems become morally unacceptable 'character defect[s]'. It is interesting how socially powerful a label can be in transforming something from a moral bad to a moral good with no other change beyond the name. The idea of a character defect 
was left unchallenged in the conversation, which implies that the existence of such a thing was accepted. It is also interesting that the challenges associated with dyslexia could even potentially be considered deficiencies in 'character', rather than difficulties with specific 'abilities'. There is arguably here an echo of our history of the 'deficient' or the 'disabled' as social misfits who have something wrong with them that is socially abhorrent. Declaring the 'disability' as a thing they want to be rid of in these conversations arguably requires a hidden acknowledgement that as individuals they are a social problem: 'for a disabled person to seek or desire a cure, worthlessness is often implied...conflict between a desire to be 'cured' and how this desire is interpreted by others is inevitable' (Carr and Hartnett, 1996: 9).

\section{Desiring dyslexia}

C: An' also, like, I guess because I found that so difficult, it kind of made me feel like

I wasn't wasting their time? and I wasn't going I dunno, be like, well, you're not dyslexic, n' you've wasted a whole day. Like, it was nice, [like ]

$H$ :

[yeah]

C: again, to feel, like, it's sort of like, understanding that you have got it, sort of [thing].

$H:[\mathrm{mmm}]$ yeah. yeah.

'[T]hat' in the first line above refers to the dyslexia assessment, and 'their' in the second line refers to the psychologist who administered the test; 'their' can be used as a reference to a single person when one does not want or need to mention the gender (i.e. 'his' or 'her') but it may also mean that $\mathrm{C}$ considers the psychologist one representative of a specific group of professionals who are involved in her diagnosis, or to mean that psychology itself is a 'they' or a 'them', an indeterminate body of experts. '[I]t kind of made me feel like I wasn't wasting their time' says C. It is interesting that $\mathrm{C}$ talks of 'their' time being wasted, rather than her own, as this arguably constructs the 'expert's' time as more valuable than hers, and by implication, the expert as more important. This line also suggests that had she not been found dyslexic, the assessor would have thought $\mathrm{C}$ to be a fraud not worthy of the attention she had got, and a time-waster. For $\mathrm{C}$ in this story, the assessor has the power to tell her for certain 
whether or not she has 'got it'. '[G]ot it' places the dyslexia as a thing (an 'it') which C possesses, and in having this thing, $\mathrm{C}$ cannot be a time-waster, but someone who was worthy the whole time. There is certainly little doubt that in this story, $\mathrm{C}$ wants to be 'diagnosed' as the alternative may have negative implications for her identity.

When constructed as a socially acceptable 'diagnosis' that is in some cases desirable as an explanation, the label itself becomes 'cherished' (Gibbs \& Elliot, 2010: 298) and something worth protecting. Below, S is talking about people who disingenuously 'went for' the dyslexia label for the resources they thought they would get.

S: when we did it in house, a lot of people weren't, weren't. I mean I might be, like, largely biased, but cos I knew there were a lot of people who went for this were sort of very lazy arrogant [people] who would take the piss out of you

$H:$ [yeah ]

S: having [dyslexia] but you know, as soon as they realised you could H: [yeah ]

S: (unclear)

H: yeah that's quite scary.

D: $\mathrm{mmm}$

S: yeah, so they might realise they do have dyslexia, but if they don't have dyslexia, then they are giving it a really bad [name]

$H:$ [yeah]

$D$ : [it ] kind of makes me feel guilty because sometimes I feel like I'm faking it, and then I'll mess something up 
[you'll, then ] you kind of do value whether you do have it or not.

S: [yeh but you don't]

We are invited to make the connection that it is the same people who went for the test disingenuously who were also lazy and arrogant and who took the piss. 'I knew' is an expression of certainty, and 'lazy' and 'arrogant' are here are presented as factual descriptions. They are further constructed as morally undeserving of the dyslexia label because they 'would take the piss out of you having dyslexia'. S acknowledges that 'they might realise they do have dyslexia' and therefore, are genuine, 'but if they don't have dyslexia, then they are giving it a really bad name'. This last suggests the label is worth protecting from imposters, and it also suggests that being dyslexic is something you can fake. If the latter is the case, it casts doubt upon the air-tight 'diagnoses' of scientific professionals. It is also possible that the more people 'diagnosed', the less unique being dyslexic becomes. Furthermore, if 'lazy' people begin to be diagnosed with dyslexia, this will taint the reputation of dyslexic people being harder-workers than others, if we follow the line of thinking drawn by $\mathrm{S}$.

D completes this extract with a wobble of self-doubt: 'kind of makes me feel guilty because sometimes I feel like I'm faking it', and this construction of guilt is undertaken by other participants other times in the focus groups. The 'I feel like' ensures others do not imagine he is actually faking it (compare with the phrase 'sometimes I am faking it' which would be morally unacceptable in this context), and he completes his sentence with an 'and then' headed clause which repositions him as undoubtedly genuine, not at all like the characters in S's narrative, and he reiterates the 'value' of 'having it'. The extract above is another in the category of those which construct a moral glow around 'being dyslexic' that is juxtaposed to the ideologically and historically constructed meanings of laziness and stupidity, and the fear of being 'vilified as lazy, ignorant or unintelligent', as Gibbs and Elliot (2010: 298) put it. A further such extract follows below:

$J:$ mmm I think, when I went and they tried to describe to me what dyslexia was, it 
[was like ] highly above average in something and then

H: [keep going ]

J: like dramatically, having that difference across the, and [test]

$G$

[yeah] and if you're just not

very good in general [then you've] obviously not got dyslexia.

J: [yeah, $\quad$ mmm]

$G:$ hhhhh

M: that's if then stupidity hhh

J's reference to 'they' in the first line indicates the educational psychologist, and preludes discussion of how dyslexia is identified. Referring to averages constructs psychology's norms and measurable individual differences as truths and common sense. J only states the 'highly above average' aspect; missing is the statement 'and greatly below average in other things' which was left unspoken. It is telling that the 'below average' part was left out, and the 'above average' was present. J's 'dramatically' also emphasises the specialness of the diagnosis, and suggests it is not something anyone can get (see Elliott \& Grigorenko, 2014 for the label as covetable).

G's response is telling of the dyslexia identity as a moral good: her 'yeah' immediately aligns her view with J's, and her line 'if you're just not very good in general then you've obviously not got dyslexia' is heavy with what it misses out. G might equally have said 'if you are just very good in general then you've obviously not got dyslexia' (first 'not' missing). In her use of 'not' G separates herself and the other participants (and others who are dyslexic) from the group of people who are 'just not very good in general'. Her 'obviously' places the separation as beyond doubt. $M$ finishes off with what seems to have been an understood but as yet unspoken sentiment 'that's if then stupidity hhh'. He states the point they have gradually constructed together, that you cannot be dyslexic and stupid (again see concerns of Elliot and Grigorenko, 2014). 


\section{Conclusion}

Dyslexia can be understood in a number of different ways, some of which link those so labelled with greater moral or social worth than others. The context is all important, as is the shared knowledge about dyslexia and education in any particular group at a given time and place. Within higher education, particularly in those institutions and disciplines where being highly literate is valued above other performances, talk about ability in reading, writing and subject knowledge (as measured by that institution) is morally loaded. Being dyslexic can be an escape from accusations of moral and intellectual inferiority which appear still to be connected to people who struggle with particular culturally valued performances like reading, writing, memorising, and expressing academic ideas quickly and articulately. However, the power of the dyslexia label to offer an escape from these undesirable positions can rest upon how dyslexia is conceptualised and by whom in any given context. The knowledge that some people think of dyslexia as a myth or an excuse, or as a kind of mental retardation, means that dyslexic students are unlikely to feel secure in the way they share their identification with others, and in their decisions about the extent to which they ought to take reasonable adjustments in the name of dyslexia.

As they move up the education system to become undergraduates and possibly postgraduates, students have arguably invested in their status as academic; and for some of the participants this seemed to mean subscribing to the construction of high literacy as a central indicator of worth, even though they might contest this position when challenged. These uncertainties were complicit in the conversations around fairness and blame in the focus group conversations. The students appeared to say they deserved help and understanding as long as they were putting in a lot of effort, and as long as there was evidence of underlying intelligence and moral worth which meant they deserved to be in academia. Arguably often present was the fear that a far worse 'character defect' (as one student put it) might be the genuine culprit, which once revealed would confirm their moral inferiority. Moral inferiority appears to invite blame: the blame of others, or the blame of oneself.

Whether or not to acknowledge dyslexia was therefore not straightforward for the participants in this study. It was a risky business. Dyslexic students, to different degrees perhaps, have to negotiate their own positions as learners with a label, and they have to accept or find ways to resist those discourses which they come across from psychologists, from stories in the press, 
online, and from their peers, families and educators. They also have to find ways of managing the way they take on identities as people with certain kinds of abilities and difficulties. This might mean playing down their difficulties in some contexts and emphasising them in others; it might mean constructing dyslexia as an innate, eternal neurological deficiency in some contexts, while at other times producing it as an environmental consequence. This is a particular burden that students without labels do not carry.

This paper argues that a more systematic and nuanced approach to staff training and student support would help to make higher education more inclusive for students with learning differences such as dyslexia. A case for such an approach in schools has already been made (see Davis \& Deponio, 2014). For practice in higher education, this would mean a move away from reliance upon generic tips for 'dealing with' dyslexic students, which may encourage teachers to feel they have ticked the inclusion box once they have attended to such a list. It would mean a move towards more systematic incorporation of staff training and development focused explicitly upon raising awareness of the politically and socially situated meaning of words like dyslexia, intelligence, equality and ability. Such training should make space for reflection upon how the ways we talk about learning and 'ability' help to produce different kinds of learner, or subtly apportion blame or praise; and would help to reveal the complexities surrounding celebration of neurodiversity within institutions functioning under capitalism (Runswick-Cole, 2014). It would also be hugely valuable to hold similar discussions with student groups during an early stage in their degree so that they can reflect upon the ways in which the educational environment can encourage them to rank themselves and each other according to grade or perceived academic ability. There is an urgent need work to explore more thoroughly how such development could be structured. 


\section{References}

American Psychiatric Association. 2013. Diagnostic and Statistical Manual of Mental Disorders (Fifth ed.) or DSM-V. Arlington, VA: American Psychiatric Publishing: 5-25. Benton, Arthur. L. and David Pearl. 1978. Dyslexia: An Appraisal of Current Knowledge. New York: Oxford University Press.

Billig, Michael. 2001. Discursive, Ideological and Ideological Messages. Reading 15 in Wetherell, Margaret, Stephanie Taylor and Simeon Yates (Eds.) 2001. Discourse, Theory and Practice: A Reader. London, Thousand Oaks, New Delhi: Sage Publications/ The Open University: 210-221

Burden, Robert. 2005. The Self-concept and its Relationships to Educational Achievement. Chapter 14 in Soler, J., Fletcher-Cambell, F and Reid, G (Eds.) 2009. Understanding Difficulties in Literacy Development: Concepts and Issues. London, Califormia, New Delhi, Singapore: Sage.

Cameron, Harriet and Karl Nunkoosing. 2012. Lecturer Perspectives on Dyslexia and Dyslexic Students Within One Faculty at One University in England. Teaching in Higher Education. 17 (3): 341-352

Carr, Wilfred and Antony Hartnett. 1996. Education and the Struggle for Democracy: The Politics of Educational Ideas. Buckingham, Philadelphia: Open University Press.

Collinson, Craig and Claire Penketh. 2009. 'Sit in the Corner and Don't Eat all the Crayons': Postgraduates with Dyslexia and the Dominant 'Lexic' Discourse. Disability \& Society. 25 (1): 7-19.

Collinson, Craig and Claire Penketh 2013. Idle chatter and alienating 'blah': rewriting literacy as a site for exclusion. International Journal of Inclusive Education, 17 (2): 143-155.

Daley, Janet. 2009. Labour MP Says the Unsayable about the Dyslexia Epidemic. The Telegraph.

http://blogs.telegraph.co.uk/news/janetdaley/8100497/Labour MP says the unsayable abou t the dyslexia_epidemic/ [Accessed 12.9.12].

Danziger, Kurt. 1990. Constructing the Subject: Historical Origins of Psychological Research. Cambridge, New York, Melbourne: Cambridge University press. 
Davies, Bronwyn and Rom Harré. 1999. Positioning and Personhood. In Rom Harre R and van Langenhove L (Eds.) Positioning Theory. Oxford and Massachusetts: Blackwell: 32-52.

Davis, John. M. and Pamela Deponio. 2014. Analysing conflicting approaches to dyslexia on a European project: moving to a more strategic, participatory, strength-based and integrated approach. International Journal of Inclusive Education, 18 (5): 515-534

Denhart, Hazel. 2008. Deconstructing barriers - perceptions of students labelled With learning disabilities in higher education. Journal of Learning disabilities. 41 (6): 483-442 Elliott, Julien. and Elena Grigorenko. 2014a. The Dyslexia Debate. New York: Cambridge University Press.

Elliott, Julien. and Elena Grigorenko. 2014b. The end of dyslexia? The Psychologist. 27: 576581

Friere, Paulo. 1996. Letters to Christina. London: Routledge.

Gee, James Paul. 2005. An Introduction to Discourse Analysis: Theory and Method. Second edition. New York, London: Routledge.

Gee, James Paul. 2009. Discourse Analysis: what makes it critical? http://www.jamespaulgee.com/sites/default/files/pub/CriticalDiscourse.pdf . Accessed 16.08.12.

Gibbs, Simon and Julian Elliott. 2010. Dyslexia: a categorical falsehood without validity or utility. Advances in Learning and Behavioral Disabilities, 23, 287-301

Giroux, Henry .A. 1997. Pedagogy and the Politics of Hope: Theory, Culture and Schooling. Colorado and Oxford: West View Press.

Goldacre, Ben. 2006. Dore - the miracle cure for dyslexia. Bad Science and the Guardian. The Guardian: http://www.badscience.net/2006/11/the-miracle-cure-for-dyslexia/ [Accessed 8.1.14].

Hacking, Ian. 1995. The Looping Effects of Human Kinds. Chapter 12 in Causal Cognition: A Multi-disciplinary Debate. D. Sperber, D. Premack, and A.J. Premack (Eds.) Cambridge, Massachusetts: Harvard university Press: 351-383.

Ho, Anita. 2004. To be labelled, or not to be labelled: that is the question. British Journal of Learning Disabilities, 32, 86-92.

Jackson, Mark. 1996. Institutional Provision for the Feeble-minded in Edwardian England. Chapter 8 in David Wright and Anne digby (Eds.). From Idiocy to Mental Deficiency: 
Historical Perspectives on People with Learning Disabilities. London and New York: Routledge: 161-183.

Lea, Mary, R. and Brian, V. Street. 1998. Student writing in higher education: an academic literacies approach. Studies in Higher Education, 23 (2): 157-173.

Macdonald, S. (2009). Towards a social reality of dyslexia. British Journal of Learning Disabilities, 38: 271-279.

Mugnaini, D., Lessi, S., La Malfa, G. and Albertini, G. (2009). Internalising correlates of dyslexia. World Journal of Pediatrics. 5 (4): 255-264.

Nicolson, Roderick. I. 2015. Positive Dyslexia. Sheffield: Rodin Books.

Nicolson, Roderick. I. and Angela Fawcett. 2008. Dyslexia, learning and the brain. Massachusetts: Massachusetts Institute of Technology.

Pollack, David. 2005. Dyslexia, the Self and Higher Education: Learning Life Histories of Students Identified as Dyslexic. Stoke on Trent: Trentham.

Runswick-Cole, Katherine. 2014. 'Us'and 'them': the limits and possibilities of a 'politics of neurodiversity’ in neoliberal times, Disability \& Society, 29 (7): 1117-1129.

Tanner, Kathleen. 2009. Adult dyslexia and the 'conundrum of failure'. Disability \& Society, 24 (6): 785-797

Thomas R Miles and Elaine Miles. 1990. Dyslexia: A Hundred Years On. Milton-Keynes and Philadelphia: Open University Press.

Rose, Nikolas. 1985. The Psychological Complex: Psychology, Politics and Society in England, 1869-1939. London and Boston: Routledge and Kegan Paul.

Stanovich, Keith, E. 1991. Discrepancy Definitions of Reading Disability: Has Intelligence Led Us Astray? Reading Research Quarterly. 26 (1): 7-29.

Stanovich, Keith, E. 2005. The future of a mistake: Will discrepancy measurement continue to make the learning disabilities field a pseudoscience? Learning Disability Quarterly. 28: 103-106.

Rutter, Michael. 1978. Prevalence and Types of Dyslexia. In Arthur L Benton and David Pearl. (Eds.)., Dyslexia: an appraisal of current knowledge. New York: Oxford University Press. 
Willig, Carla. 2008. Introducing Qualitative Research in Psychology. Second Edition.

Berkshire and New York, Open University Press. 